\title{
Simple and double microencapsulation of Lactobacillus acidophilus with chitosan using spray drying
}

\author{
Isela A. Flores-Belmonta ${ }^{a}$, Enrique Palou ${ }^{a}$, Aurelio López-Malo ${ }^{a}$, And María \\ TERESA JimÉnEZ-Munguía ${ }^{a^{*}}$ \\ a Departamento de Ingeniería Química, Alimentos y Ambiental, Universidad de las Américas Puebla, \\ Ex-hacienda Sta. Catarina Mártir, San Andrés, Cholula, Puebla, 72810, Mexico \\ *Corresponding author \\ mariat.jimenez@udlap.mx \\ TEL: $+52-222-229-2729$ \\ FAX: $+52-222-229-2126$ \\ Received: 15 July 2014; Published online: 18 October 2015 \\ Invited paper from the $3^{\text {rd }}$ International ISEKI_Food Conference - ISEKI_Food 2014 - Bridging Training and \\ Research for Industry and the Wider Community - Food Science and Technology Excellence for a Sustainable \\ Bioeconomy
}

\begin{abstract}
The aim of this study was to evaluate the survival of Lactobacillus acidophilus that had been simple or double spray dried using chitosan to cause microencapsulation and which had been exposed to model gastrointestinal conditions. In addition, the study also determined the physicochemical properties of the powder containing the microencapsulated probiotic.

Chitosan-inulin or chitosan-maltodextrin (1:15 or 1:25) solutions were inoculated with $10^{12} \mathrm{CFU} \mathrm{mL}^{-1}$ of $L$. acidophilus, for simple microencapsulation. The different solutions were dried using a spray dryer with an inlet air temperature of $130{ }^{\circ} \mathrm{C}$ and a solution flux of $4.8 \mathrm{~g} \mathrm{~min}^{-1}$. A two-step process was used for the double microencapsulation. In the first step, the probiotic was added to a gelatin-maltodextrin (1:25) solution and then spray dried; for the second step, the microencapsulated probiotic was added to a chitosan-inulin or chitosan-maltodextrin (1:25) solution and then it was spray dried again.

With the simple microencapsulated probiotic, a microbial reduction of 7 log cycles was obtained. With the double microencapsulated probiotic only $3 \log$ reductions were achieved. The double microencapsulated probiotic thus demonstrated greater resistance to simulated gastrointestinal conditions. The powders produced were shown to have water activity values of $0.176-0.261$ at $25{ }^{\circ} \mathrm{C}$ and moisture content of $0.8-1.0 \%$, which are characteristic of spray dried products. The bulk density was significantly $(\mathrm{p}<0.05)$ lower $\left(300 \mathrm{~kg} \mathrm{~m}^{-3}\right)$ for simple than for double $\left(400 \mathrm{~kg} \mathrm{~m}^{-3}\right)$ microencapsulated probiotic powders. Solubility and dispersibility of the powder microcapsules were better at lower $\mathrm{pH}$ values. Double microencapsulation using a process of spray drying is therefore recommended for probiotics, thus exploiting chitosan's insolubility in water, which can be applied for the of development food products.
\end{abstract}

Keywords: Encapsulation; Probiotics; Microcapsules; Physicochemical powder properties 


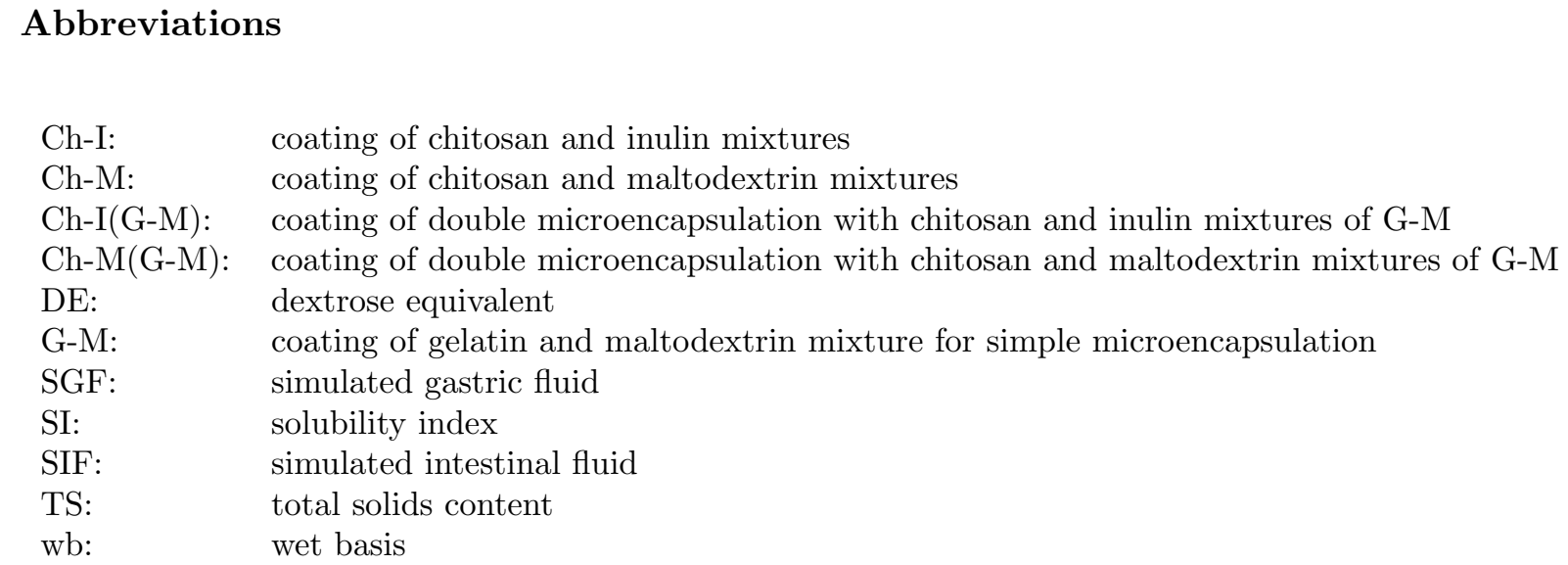

\section{Introduction}

Functional foods that contain probiotics are continuously increasing in the global market (Amin, Thakur, Jain, et al., 2013). Probiotics especially have been added to dairy products like fermented milk, yogurt, cheese, butter, ice-cream or milkdrink beverages, and have been developed more than any other food product group (Kailasapathy, 2006; Karimi, Mortazavian, \& Da Cruz, 2011; Di Criscio et al., 2010). Non-dairy food products such as fruit and vegetables drinks, soy, cereals and meat products with probiotics have been recently tested (Barboza, Marquez, Parra, Patricia Pinero, \& Medina, 2012; Gawkowski \& Chikindas, 2013; Granato, Branco, Nazzaro, Cruz, \& Faria, 2010). It has been noted that desired levels of the survival of probiotics at suggested concentration of $10^{7} \mathrm{CFU} \mathrm{g}^{-1}$ in the final food product to assure the beneficial effects in the body (FAO/WHO, 2006) are not always retained. Therefore, the evaluation of functionality of food formulated with probiotics under model gastrointestinal conditions in vitro is suggested (Gbassi \& Vandamme, 2012). Different probiotic strains (Lactobacillus spp. and Bifidobacterium spp.) have also been studied to evaluate their resistance to acid conditions and bile salts. Of these, Lactobacillus acidophilus and L. salivarius were the most acid-tolerant and just as susceptible to bile salt exposure as Bifidobacterium spp. (Ding \& Shah, 2007).

Several microencapsulation techniques (extrusion, emulsion, freeze-drying and spray drying) have also been proposed to enhance probiotics survival during food processing, storage and the passage through the gastrointestinal tract (Amin et al., 2013; Anal \& Singh, 2007). The efficacy of each technique is dependent on the bacteria strain (its resistance to the stress factors within the microencapsulation process and further release), the wall material used (physicochemical properties and stability), the cost-effectiveness of the microencapsulated probiotic, the final application in a food product (fluid, semi-fluid or solid) and its storage temperature (freeze, refrigeration or room temperature) (Rokka \& Rantamaki, 2010).

Probiotic microencapsulation through a process of spray drying has been studied from different perspectives, mainly testing different coating materials and process conditions, in the aim of ensuring probiotics viability, stability and a wider application in food products (Amin et al., 2013; Corona-Hernandez et al., 2013; Gharsallaoui, Roudaut, Chambin, Voilley, \& Saurel, 2007). The commonly used coating materials for spray drying microencapsulation are carbohydrates (dextroses, maltodextrins, starches, gum arabic, alginate, inulin, fructo-oligosaccharides and chitosan), proteins (whey protein, gelatin and skimmed milk) and lipids (vegetable oils) (Estevinho, Rocha, Santos, \& Alves, 2013; Fritzen-Freire et al., 2012; Rokka \& Rantamaki, 2010). Some selection criteria for the coating material used are based on the physicochemical properties, solubility, viscosity in the prepared solution, the compatibility with the core-material and the intended size and surface of the final mi- 
$190 \mid$ Flores-Belmont et al.

crocapsules (Chávez \& Ledeboer, 2007). Since the use of a single material does not satisfy all desired requirements, the combination of different coating materials has been suggested to be used in mixture or to create multilayers (Desai \& Park, 2005).

Chitosan is a cationic polymer obtained with different degrees of deacetylation $(40-98 \%)$ of chitin (N-acetyl-glucosamine polymer) and having a molecular weight of $50-2000 \mathrm{kDa}$; these parameters determine characteristics like crystallinity, biodegradability and viscosity when it is dissolved in solvent systems (Estevinho et al., 2013). The microcapsules obtained by spray drying when using chitosan are characterized by high sphericity and low water vapour sorptivity, they are therefore very stable during storage, and demonstrate controlled release characteristics caused by its low solubility at neutral pH values (Adamiec \& Modrzejewska, 2005). Chitosan has been applied as coating material for spray drying microencapsulation of a wide variety of pharmaceutical products, enzymes, emulsions and vitamins (Estevinho et al., 2013). While there are many studies concerning probiotic microencapsulation with chitosan by the extrusion technique (Rokka \& Rantamaki, 2010; Teoh, Mirhosseini, Mustafa, Hussin, \& Manap, 2011), not much information has been found regarding probiotic spray drying microencapsulation using chitosan as coating material. Chitosan has antimicrobial activity which may necessitate the use of other coating materials as co-protectors or a two-step microencapsulation (Amin et al., 2013; Ivanovska et al., 2012; Teoh et al., 2011).

The objectives of this study were to evaluate the survival of Lactobacillus acidophilus that had been simple or double spray dried using chitosan for microencapsulation and which had been exposed to model gastrointestinal conditions. In addition, the study also determined the physicochemical and physical properties of microencapsulated probiotic in powder.

\section{Materials and Methods}

\subsection{Materials}

\section{Probiotic culture}

The probiotic strain used in this study was Lactobacillus acidophilus NRRL (B-4495), donated by the Agriculture Research Services Department of the USDA to the Food Microbiology Laboratory of Universidad de las Américas Puebla (UDLAP). This strain was cultivated in Man, Rogosa \& Sharpe (MRS) agar (DB Difco, France), anaerobically at $35-37{ }^{\circ} \mathrm{C}$. L. acidophilus was then adapted to $40{ }^{\circ} \mathrm{C}$ in MRS broth (DB Difco, France) to increase its thermal resistance when submitted to spray drying.

\section{Coating agents}

The coating materials used were chitosan with deacetylation degree $>75 \%$ (Sigma, Mexico), maltodextrin 10 DE (Globe 19100, Mexico), agave inulin (Fructagave, Mexico) and gelatin (Gelco SA, Colombia).

\subsection{Methods}

\section{Simple and double microencapsulation}

Mixtures of chitosan-inulin (Ch-I) (1:15 or 1:25), chitosan-maltodextrin (Ch-M) (1:15 or $1: 25)$ and gelatin-maltodextrin (G-M) (1:25), at $26 \% \mathrm{w} / \mathrm{w}$, were dissolved with stirring in ascorbic acid solution at $1 \%$. For simple microencapsulation these solutions were inoculated with $10^{12} \mathrm{CFU}$ $\mathrm{mL}^{-1}$ of L. acidophilus. The different solutions were atomized using a spray dryer (B-290, Büchi Laboertechnik, Switzerland) with an inlet air temperature of $130{ }^{\circ} \mathrm{C}$ and a solution flux of $4.8 \mathrm{~g}$ $\mathrm{min}^{-1}$. A two-step process was used for the double microencapsulation. In the first step, the probiotic was added to G-M (1:25) aqueous solution and then was spray dried with the same process conditions as for the simple microencapsulation; for the second step, one gram of the microencapsulated probiotic was added to $100 \mathrm{~mL}$ of Ch-I or Ch-M (1:25) solutions previously prepared, and 
then spray dried using the same process conditions as in the first step.

\section{L. acidophilus viability}

The microencapsulated probiotic viability was determined by microbial survival count, $1 \mathrm{~g}$ of the microencapsulated probiotic powder was dispersed in $9 \mathrm{~mL}$ sterile peptone water $(0.1 \%)$. Solutions were serially diluted $\left(10^{-1}\right.$ to $\left.10^{-9}\right)$ to determine bacterial enumeration (30- $300 \mathrm{CFU}$ plate $^{-1}$ ) in MRS agar (DB Difco, France). The process was carried out in triplicate. Inoculated plates were incubated at $35-37{ }^{\circ} \mathrm{C}$ under anaerobic conditions and, colonies were counted after 48 h (Hernández-Carranza, López-Malo, \& Jiménez-Munguía, 2013).

\section{Gastrointestinal model simulation}

According to the USP (2002), simulated gastric fluid (SGF) $(2 \mathrm{~g} \mathrm{NaCl}, 3.2 \mathrm{~g}$ pepsin, $7 \mathrm{~mL}$ of $\mathrm{HCl}$, made up to $1 \mathrm{~L}$ volume and adjusted to $\mathrm{pH}$ of 2.0) and simulated intestinal fluid (SIF) (6.8 g $\mathrm{KH}_{2} \mathrm{PO}_{4}, 10 \mathrm{~g}$ pancreatin, $190 \mathrm{~mL}$ of $\mathrm{NaOH}$ $0.2 \mathrm{~N}$, made up to $1 \mathrm{~L}$ volume, and adjusted to $\mathrm{pH}$ of 7.0) were formulated. $1 \mathrm{~g}$ of the microencapsulated probiotic powder was added to $9 \mathrm{~mL}$ of SGF and incubated at $35^{\circ} \mathrm{C}$ for $2 \mathrm{~h}$, and then $1 \mathrm{~mL}$ of this preparation was added to $9 \mathrm{~mL}$ of $\mathrm{SIF}$ and was incubated at $35{ }^{\circ} \mathrm{C}$ for $3 \mathrm{~h}$. At the beginning and after each step of the gastrointestinal model simulation, L. acidophilus viability was determined as described in section 2.2.2.

\section{Physical properties of powders}

The measurements of the physical properties of the powders were conducted in triplicate. Particle diameter of the powders was measured with a particle analyzer (Bluewave S3500, Microtrac, USA). Bulk density $\left(\rho_{b}\right)$ was determined by calculation of the relation of mass and volume of the powder, specific mass of powder was weighed and poured into a cylinder $(10 \mathrm{~mL})$ without tapping. Tapped density $\left(\rho_{t}\right)$ was determined by manually tapping the cylinder 250 times and recording the final volume occupied by the powder. Particle density $\left(\rho_{p}\right)$ or apparent density was determined by recording the volume occupied in a cylinder of a known quantity of powder and 6 $\mathrm{mL}$ of petroleum ether as described by Telang and Thorat (2010). Powder porosity $(\varepsilon)$ was calculated as: $\varepsilon=1-\left(\rho_{b} / \rho_{p}\right)$.

\section{Phsysicochemical properties of powders}

Water activity $\left(\mathrm{a}_{w}\right)$ was measured using a hygrometer (Aqua lab, Mod. 3TE, Decagon Devices Inc., USA). Moisture content was determined by the 925.45 AOAC method (AOAC, 2000). Hygroscopicity was determined by exposing $1 \mathrm{~g}$ of powder to $75 \%$ relative humidity, using supersaturated $\mathrm{NaCl}$ solution at $25^{\circ} \mathrm{C}$. The powder weight change was recorded every 2 days to constant weight until a weight difference of $0.001 \mathrm{~g}$ between sequential data was recorded. The measurements of $\mathrm{a}_{w}$ and moisture content of the powders were conducted in triplicate, and the moisture gain kinetic for the hygroscopicity property was carried out in duplicate.

\section{Reconstitution properties of powders}

The reconstitution properties of microencapsulated powders were determined, in triplicate, in aqueous solutions adjusted to $\mathrm{pH} 3.0,5.0$ or 7.0. Immersion time was determined as the time needed for $1 \mathrm{~g}$ of powder to disappear from the surface of $200 \mathrm{~mL}$ of solution, no stirring applied. For the dispersibility test, $10 \mathrm{~g}$ of powder was poured into $9 \mathrm{~mL}$ of the solution, then particle size distributions were measured with a particle analyzer (Bluewave S3500, Microtrac, USA), every minute, during $10 \mathrm{~min}$, setting a flow of 12 $\mathrm{mL} \min ^{-1}$; the different $\mathrm{pH}$ solutions were used as carrier liquid for the measurements. Solubility test was performed as described by Telang and Thorat (2010) with some modifications; $1.3 \mathrm{~g}$ of powder in $10 \mathrm{~mL}$ of solution was centrifuged at 1,000 rpm for $5 \mathrm{~min}$ and total solids content (TS) was determined in the residue, by the 925.45 AOAC method (AOAC, 2000). Solubility index (SI) was calculated as the solids solubilized in the solutions after centrifugation: $\mathrm{SI}=(1.3-\mathrm{TS}) /$ 1.3 . 


\section{Statistical analysis}

To determine significant differences among the different treatments, analysis of variance (ANOVA) and Tukey tests were applied to the data with a confidence level of $95 \%(\alpha=0.05)$, using Minitab v.16.0 software (Minitab Inc., USA).

\section{Results and Discussion}

\subsection{Probiotic survival}

\section{Spray drying process}

The use of chitosan as coating material by spray drying produced powders with good stability; however, its known antimicrobial properties were of great concern for probiotic encapsulation thus the viability of the encapsulated bacteria had to be evaluated. In the present study, simple microencapsulation using a mixture Ch-M or Ch-I was performed comparing two proportions (1:15 and 1:25). Results of L. acidophilus population reductions after spray drying (Table 1) demonstrated that only for the coating mixture of Ch-M, the proportion of 1:25 was significantly smaller $(\mathrm{p}<0.05)$ than the proportion of $1: 15$. This result could be attributed to the increase of solids in the sprayed solution which presumably promoted a better protection against thermal damage (Avila-Reyes, Garcia-Suarez, Teresa Jimenez, San Martin-Gonzalez, \& Bello-Perez, 2014; Desmond, Ross, O'Callaghan, Fitzgerald, \& Stanton, 2002). Nevertheless, the log reductions of the bacteria were very high $(>7.13 \mathrm{log}$ cycles). These could be due to the antimicrobial property of chitosan; cationic materials such as chitosan are mediated by electrostatic forces with negatively charged parts of bacteria cell wall, due to competition with available calcium ions, resulting in cell wall disruption (Corona-Hernandez et al., 2013). Therefore, to reduce the probiotic cell damage, a double microencapsulation was proposed, first encapsulating with G-M and then microencapsulation using a mixture of Ch$\mathrm{M}$ or Ch-I, avoiding the direct contact of chitosan with the bacteria. For the double encapsulation, Ch-M(G-M) and Ch-I(G-M), L. acidophilus only demostrated log reductions of 2.77 and 3.03 re- spectively, after the spray drying process. Similar reductions were obtained by Ivanovska et al. (2012) when double microencapsulating L. casei, first using alginate and fructooligosaccharide solutions for spray-drying and then using chitosan and calcium chloride for complexation with the alginate and finally freeze drying, demonstred $2.67 \log$ reductions.

\section{Gastrointestinal model conditions}

One of the main advantages of using chitosan is its ability to protect probiotics in simulated gastrointestinal fluids, nevertheless in literature this has been demonstrated only for microencapsulation by the extrusion technique with chitosan and alginate beads freeze-dried, spray-dried or not (Lee, Cha, \& Park, 2004; Ivanovska et al., 2012; Teoh et al., 2011; Urbanska, Bhathena, \& Prakash, 2007). In most of the cases, the comparison between non-encapsulated probiotic cells and microencapsulated with chitosan have shown that there is 5 to $6 \mathrm{log}$ cycles of difference. In our study, L. acidophilus free cells were also exposed to SGF and after $2 \mathrm{~h}, 6.23 \mathrm{log}$ cycle reductions were obtained. Probiotic population with simple encapsulation in G-M had a reduction of $5.21 \mathrm{log}$ cycles while for the double encapsulation of the probiotic with Ch-M(G-M) or Ch-I(G-M), the population reduction reported was of $1.1 \mathrm{log}$ cycles. The subsequent exposure of these cells to SIF for $3 \mathrm{~h}$, resulted in a smaller additional log cycles reduction, demonstrating a total probiotic reduction of 1.65 and 1.84 cycles for the double encapsulation with Ch-M(G-M) or Ch$\mathrm{I}(\mathrm{G}-\mathrm{M})$, in contrast to 5.84 and $7.00 \mathrm{log}$ cycles for the simple microencapsulated probiotic with G-M and free cells respectively (Fig. 1). The slightly higher survival levels noted when using the mixture coating of Ch-I(G-M) could be due to the high solubility of inulin at neutral $\mathrm{pH}$ values. Besides, prebiotics have been recommended for use as co-protectants for microencapsulation, promoting a further bacteria proliferation once these are released in the colon (Chen, Chen, Liu, Lin, \& Chiu, 2005; Corcoran, Ross, Fitzgerald, \& Stanton, 2004). 
Spray-drying microencapsulation of Lactobacillus acidophilus with chitosan |193

Table 1: Survival and log reductions of L. acidophilus after simple or double microencapsulation by spray drying

\begin{tabular}{lllccc}
\hline \multirow{2}{*}{ Microencapsulation } & \multicolumn{2}{c}{ Coating mixture } & $\begin{array}{c}\text { Initial population } \\
\left(\mathrm{CFU} \mathrm{g}^{-1}\right)\end{array}$ & $\begin{array}{c}\text { Final population } \\
\left.(\mathrm{CFU} \mathrm{g})^{-1}\right)\end{array}$ & Log reduction \\
\cline { 2 - 5 } Simple & Material & Proportion & $9.90 \times 10^{13}$ & $2.50 \times 10^{6}$ & $7.58 \pm 0.02^{a}$ \\
& Ch-M & $01: 15$ & $9.90 \times 10^{13}$ & $3.70 \times 10^{6}$ & $7.45 \pm 0.03^{b}$ \\
& & $01: 25$ & $7.20 \times 10^{14}$ & $5.20 \times 10^{7}$ & $7.13 \pm 0.02^{c}$ \\
\multirow{5}{*}{ Double } & Ch-I & $01: 15$ & $5.80 \times 10^{14}$ & $3.30 \times 10^{7}$ & $7.21 \pm 0.04^{c}$ \\
& G-M & $01: 25$ & $3.45 \times 10^{13}$ & $4.30 \times 10^{12}$ & $0.93 \pm 0.01^{d}$ \\
& Ch-M(G-M) & $01: 25$ & $3.60 \times 10^{12}$ & $6.05 \times 10^{9}$ & $2.77 \pm 0.01^{e}$ \\
& Ch-I (G-M) & $01: 25$ & $3.60 \times 10^{12}$ & $3.17 \times 10^{9}$ & $3.03 \pm 0.03^{f}$ \\
\hline
\end{tabular}

${ }^{a-f}$ Different letters in the same column indicate significant difference $(\mathrm{p}<0.05)$ by Tukey test Ch: chitosan, M: maltodextrin, I: inulin, G: gelatin

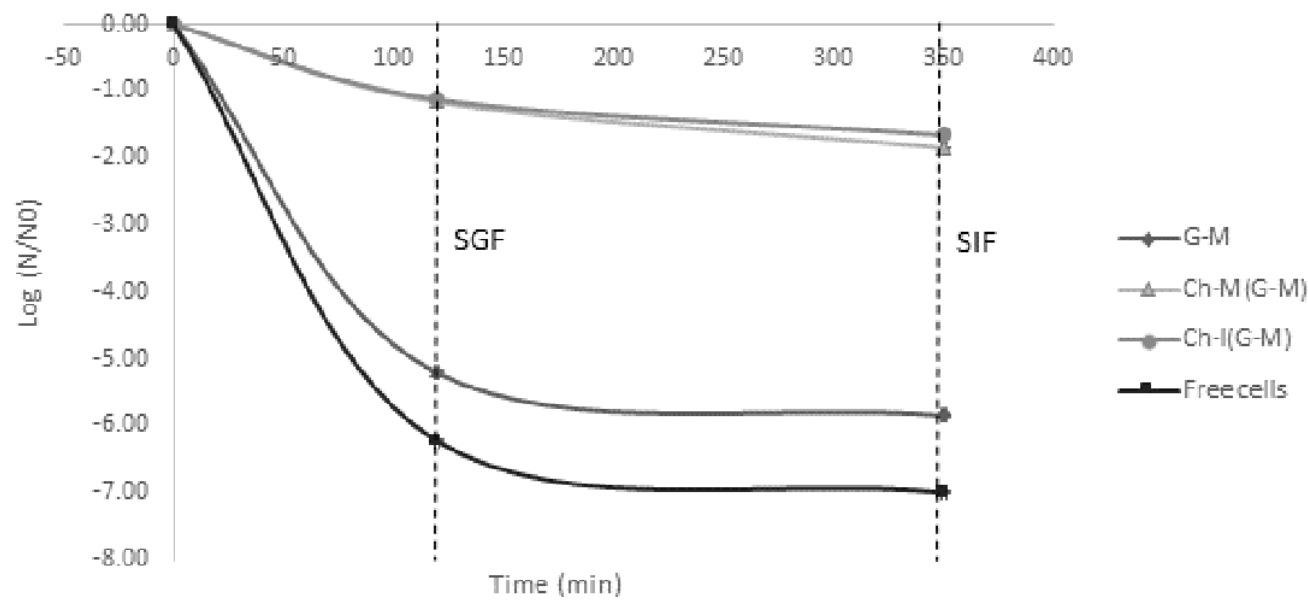

Figure 1: Survival of L. acidophilus exposed to simulated gastric fluid (SGF) and simulated intestinal fluid (SIF), non-microencapsulated (free cells), simple microencapsulated (G-M) and double microencapsulated (Ch-M(G-M), Ch-I(G-M)). G: gelatin, M: maltodextrin, Ch: chitosan, I: inulin 


\subsection{Properties of encapsulated probiotic powders}

\section{Physical properties}

Spray dried microcapsules commonly have a particle diameter range of 5 to $100 \mu \mathrm{m}$ (FritzenFreire et al., 2012; Hernández-Carranza et al., 2013; Rokka \& Rantamaki, 2010). It has been reported that small particle sizes facilitates a greater contact surface for the nutrients availability (Avila-Reyes et al., 2014). Besides, microencapsulates with mean sizes smaller than $100 \mu \mathrm{m}$ do not affect palatability of food products when these are incorporated (Corona-Hernandez et al., 2013). Our results correspond to the particle size reported in literature of spray drying microencapsulation of probiotics, presenting a particle median diameter average for the simple microencapsulated probiotic of $11.39 \mu \mathrm{m}$, while for the double microencapsulated probiotic median diameters with $\mathrm{Ch}-\mathrm{M}(\mathrm{G}-\mathrm{M})$ and $\mathrm{Ch}-\mathrm{I}(\mathrm{G}-\mathrm{M})$ were 13.94 and $21.37 \mu \mathrm{m}$, respectively. The double microencapsulated probiotic showed a wider particle distribution than the simple microencapsulated ones, with significantly higher bulk density $\left(\rho_{b}\right)$ values $\left(378-400 \mathrm{~kg} \mathrm{~m}^{-3}\right)(\mathrm{p}<0.05)$ and lower powder porosity $(\varepsilon=0.80)$ (Table 2$)$. A heterogeneous particle distribution allows the rearrangement of the individual particles and consequently a more compact powder (Fuchs et al., 2006). For this reason, tapped densities $\left(\rho_{t}\right)$ for the double microencapsulating probiotic powders were also significantly higher $(\mathrm{p}<0.05)$ than the rest of the powders.

\section{Physicochemical properties}

Coating materials composition determines microcapsule stability during storage because the materials are strongly related to the final physicochemical properties of the spray dried powders (Rokka \& Rantamaki, 2010). The obtained $\mathrm{a}_{w}$ values in this study are in the range of 0.144 - 0.261 (Table 3). According to the statistical analysis, the simple microcapsules with a higher proportion of the coating material (1:25) demonstrated significantly higher $\mathrm{a}_{w}$ values $(\mathrm{p}<0.05)$. The increase of the solids content in the suspensions to be spray dried may have retained more water molecules embedded in the obtained microcapsules, therefore increasing $\mathrm{a}_{w}$. In a previous study, Avila-Reyes et al. (2014) presented $\mathrm{a}_{w}$ values in a range of $0.200-0.240$ when using inulin as coating material, similar to the $\mathrm{a}_{w}$ value (0.233) obtained with the double microencapsulation mixture with inulin, Ch-I(G$\mathrm{M})$ in the present study. Simple and double layered microcapsules showed $\mathrm{a}_{w}$ values below 0.300 , which is characteristic of spray-dried products with good stability during storage (Ananta, Volkert, \& Knorr, 2005; Fritzen-Freire et al., 2012).

With respect to the moisture content, the powders showed values ranging from $0.84-1.87 \%$ (wb), with no significant difference $(\mathrm{p}>0.05)$ between the different systems studied, except for the microcapsules obtained for simple probiotic microencapsulation with G-M (Table 3). This result may be related to the good entrapment properties of gelatin and fast coat forming during spray drying (Gharsallaoui et al., 2007; Rokka \& Rantamaki, 2010).

Besides moisture content and water activity $\left(\mathrm{a}_{w}\right)$, the hygroscopicity of powders helps to determine associated problems due to caking or agglomeration during storage. For this reason, moisture gain of powders was evaluated at $75 \%$ of relative humidity (Fig. 2). It is showed that simple microcapsules with inulin in the coating mixture (Ch-I) presented the highest moisture gain $\left(0.30 \mathrm{~g} \mathrm{H}_{2} \mathrm{O} \mathrm{g}{ }^{-1}\right)$, while the double microcapsules Ch-I(G-M) and Ch-M(G-M) gained $0.20 \mathrm{~g} \mathrm{H}_{2} \mathrm{O} \mathrm{g}^{-1}$. The chemical structure of inulin has a large number of available bonds for hydrogen bonding and therefore easily captures water molecules present in the environment; this is why it is usually used in mixture with other coating materials for spray drying microencapsulation (Corona-Hernandez et al., 2013).

\section{Reconstitution properties}

The reconstitution properties were determined in the microcapsules that showed a higher probiotic survival after single or double microencapsulation, in order to know the different $\mathrm{pH}$ conditions in which the release of the probiotics takes place easily and consider it for its further application in foodstuff. 
Spray-drying microencapsulation of Lactobacillus acidophilus with chitosan $\mid 195$

Table 2: Bulk, tapped and particle densities of simple or double microencapsulated L. acidophilus

\begin{tabular}{lllcccc}
\hline \multirow{2}{*}{$\begin{array}{l}\text { Micro- } \\
\text { encapsulation }\end{array}$} & \multicolumn{2}{c}{ Coating mixture } & & \multicolumn{3}{c}{ Density $\left(\mathrm{kg} \mathrm{m}^{-3}\right)$} \\
\cline { 2 - 6 } & Material & Proportion & $\rho_{b}$ & $\rho_{t}$ & $\rho_{p}$ & $\varepsilon$ \\
\hline \multirow{4}{*}{ Simple } & Ch-M & $01: 15$ & $303.23 \pm 0.01^{a}$ & $526.64 \pm 0.02^{a}$ & $5004.25 \pm 0.35^{a}$ & $0.94 \pm 0.00^{a}$ \\
& & $01: 25$ & $303.24 \pm 0.02^{a}$ & $526.68 \pm 0.04^{a}$ & $5003.75 \pm 0.35^{a}$ & $0.94 \pm 0.00^{a}$ \\
& & $01: 15$ & $322.77 \pm 0.01^{b}$ & $476.46 \pm 0.02^{a}$ & $2505.63 \pm 0.53^{b}$ & $0.87 \pm 0.00^{b}$ \\
& Ch-I & $01: 25$ & $328.03 \pm 0.02^{c}$ & $476.43 \pm 0.03^{a}$ & $2501.88 \pm 0.18^{c}$ & $0.86 \pm 0.00^{c}$ \\
Double & G-M & $01: 25$ & $417.11 \pm 0.13^{d}$ & $625.67 \pm 0.20^{b}$ & $5007.25 \pm 0.35^{d}$ & $0.92 \pm 0.00^{d}$ \\
& Ch-M(G-M) & $01: 25$ & $400.48 \pm 0.08^{d}$ & $715.14 \pm 0.15^{c}$ & $2005.50 \pm 0.14^{e}$ & $0.80 \pm 0.00^{e}$ \\
& Ch-I (G-M) & $01: 25$ & $378.00 \pm 0.05^{d}$ & $742.10 \pm 0.01^{d}$ & $2002.60 \pm 0.00^{d}$ & $0.81 \pm 0.00^{f}$ \\
\hline
\end{tabular}

${ }^{a-f}$ Different letters in the same column indicate significant difference $(\mathrm{p}<0.05)$ by Tukey test

Ch: chitosan, M: maltodextrin, I: inulin, G: gelatin

$\rho_{b}$ : Bulk density, $\rho_{t}$ : tapped density, $\rho_{p}$ : particle density, $\varepsilon$ : porosity

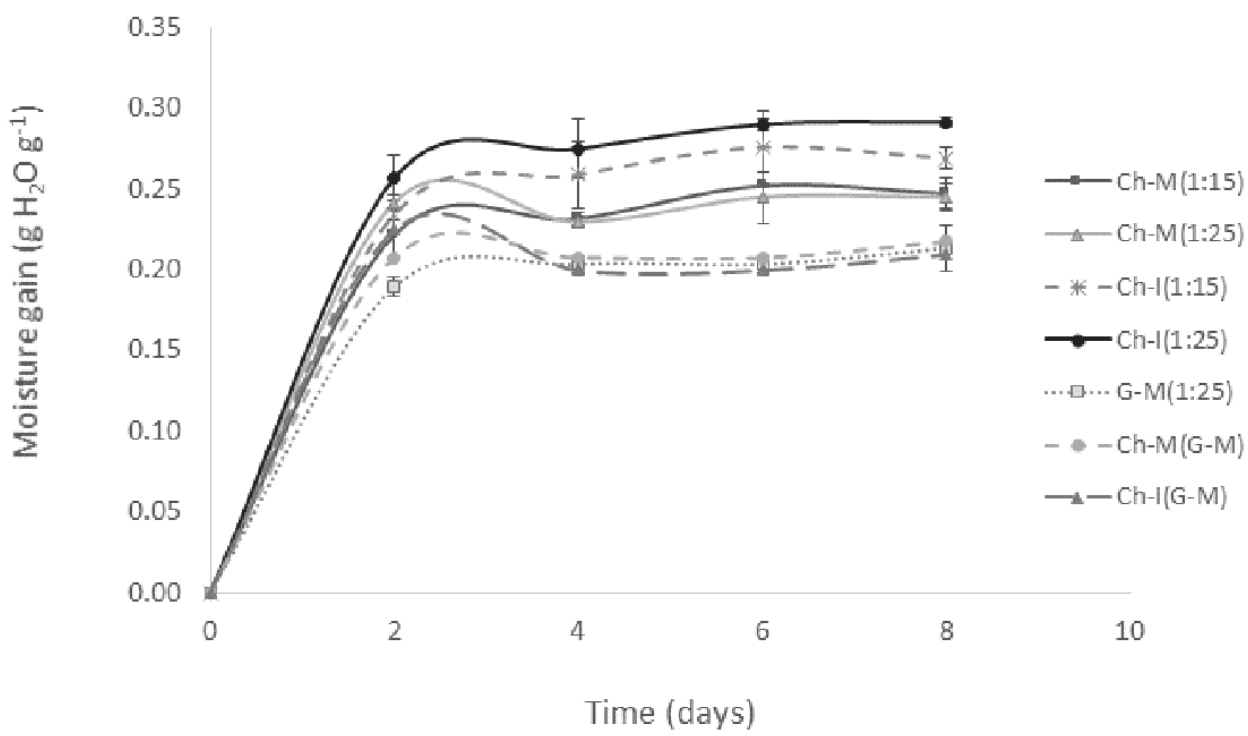

Figure 2: Moisture gain of simple microencapsulated or double microencapsulated L. acidophilus with different mixtures of coating materials and proportions (G: gelatin, M: maltodextrin, Ch: chitosan, I: inulin), at $75 \%$ of relative humidity and $25{ }^{\circ} \mathrm{C}$ 
$196 \mid$ Flores-Belmont et al.

Table 3: Physicochemical properties of simple or double microencapsulated L. acidophilus

\begin{tabular}{|c|c|c|c|c|}
\hline \multirow[t]{2}{*}{ Microencapsulation } & \multicolumn{2}{|c|}{ Coating mixture } & \multirow{2}{*}{$\mathrm{a}_{w}$} & \multirow{2}{*}{$\begin{array}{c}\text { Moisture } \\
(\% \text { wb) }\end{array}$} \\
\hline & Material & Proportion & & \\
\hline \multirow{5}{*}{ Simple } & \multirow{2}{*}{ Ch-M } & $01: 15$ & $0.178 \pm 0.002^{a}$ & $0.84 \pm 0.01^{a}$ \\
\hline & & $01: 25$ & $0.255 \pm 0.001^{b}$ & $0.98 \pm 0.01^{a}$ \\
\hline & \multirow{2}{*}{ Ch-I } & $01: 15$ & $0.197 \pm 0.002^{a}$ & $1.01 \pm 0.03^{a}$ \\
\hline & & $01: 25$ & $0.261 \pm 0.001^{b}$ & $1.00 \pm 0.14^{a}$ \\
\hline & G-M & $01: 25$ & $0.232 \pm 0.001^{b}$ & $1.87 \pm 0.33^{b}$ \\
\hline \multirow{2}{*}{ Double } & Ch-M(G-M) & $01: 25$ & $0.144 \pm 0.001^{c}$ & $0.98 \pm 0.03^{a}$ \\
\hline & Ch-I(G-M) & $01: 25$ & $0.233 \pm 0.001^{b}$ & $1.06 \pm 0.01^{a}$ \\
\hline
\end{tabular}

${ }^{a-c}$ Different letters in the same column indicate significant difference $(\mathrm{p}<0.05)$ by Tukey test Ch: chitosan, M: maltodextrin, I: inulin, G: gelatin $\mathrm{a}_{w}$ : water activity

According to Schubert (1987), powders poured on a liquid follows four stages: a) wettability (penetration of the liquid into the porosity of the powder by capillarity), b) sinkability (sinking of the particles below the liquid surface), c) dispersability (dispersion of the powder under stirring) and d) solubility (solution of the particles in the liquid). For instant powders, these stages are expected to occur in order of seconds. In the case of microcapsules by spray drying, these reconstitution properties may not take place in order of seconds but minutes, because the particles do not have significant particle porosity nor do they possess powder porosity as agglomerates powders may have. However, these properties give a good estimate of the powder behaviour in different media. The reconstitution properties determined in this study in three different $\mathrm{pH}$ values $(3.0,5.0$ or 7.0$)$ were: immersion time (related to sinkability), dispersibility and solubility. The immersion time and solubility of simple microencapsulated probiotic in G-M and double microencapsulated in Ch-M(G-M) or Ch-I(G-M) are presented in Table 4. For all the evaluated microcapsules, the immersion time was more than $5 \mathrm{~min}$ for the different solutions adjusted to different $\mathrm{pH}$ values, while the solubility test did demonstrate differences $(\mathrm{p}<0.05)$ among the different powders and solutions. Results showed that simple microcapsules with G-M were completely solubilized in all the solutions adjusted at different $\mathrm{pH}$ values ( $\mathrm{SI}=1.0)$, while double microcapsules presented $\mathrm{SI}<0.5$, demon- strating lower SI values with higher $\mathrm{pH}$ values. The coating mixture containing inulin, Ch-I(G$\mathrm{M})$, resulted in a more soluble powder than the coating mixture with maltodextrin, Ch-M(G-M). This behaviour is attributed to the hydrolysis of the inulin which undergoes at $\mathrm{pH}$ values below 4.0 .

In the dispersibility test (Fig. 3), the effect of $\mathrm{pH}$ was not clearly demonstrated for the simple microencapsulated probiotic (G-M), significant overlap of the particle distributions occurred in all tested times, which means that particles were solubilized rapidly. Meanwhile, with the double microencapsulated probiotic $\mathrm{Ch}-\mathrm{M}(\mathrm{G}-\mathrm{M})$ and $\mathrm{Ch}-\mathrm{I}(\mathrm{G}-\mathrm{M})$, agglomerates were formed at the beginning of the test and later showed a gradual dispersion over time, with smaller particle sizes detected. Besides, in accordance with the solubility test, the double microencapsulated probiotic with inulin, Ch-I(G-M), also showed smaller particle sizes at lower $\mathrm{pH}$ values than with maltodextrin in the coating mixture, Ch-M(G-M). These reconstitution tests are of great interest since the level of effectiveness of chitosan and gelatin as coating materials in simple and double microencapsulation could be demonstrated, even if the powders were formulated with a small quantity of these materials, which are highly responsible of the slow particle solubility and dispersibility in solutions adjusted to different $\mathrm{pH}$ values. 
Spray-drying microencapsulation of Lactobacillus acidophilus with chitosan |197

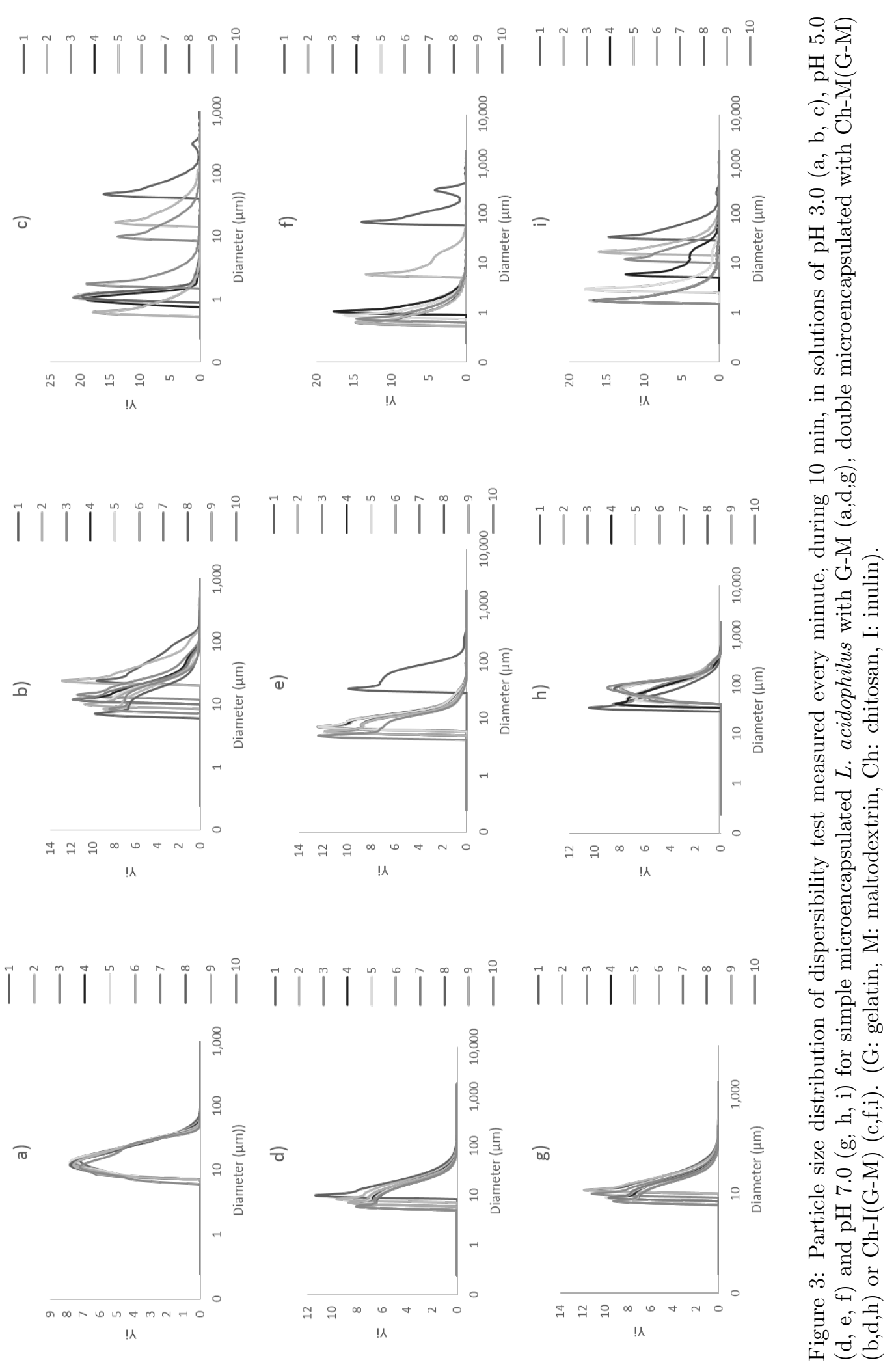

IJFS | October 2015 | Volume 4 | pages 188-200 
198 | Flores-Belmont et al.

Table 4: Reconstitution properties of simple or double microencapsulated L. acidophilus

\begin{tabular}{llccc}
\hline Microencapsulation & Coating mixture & $\mathrm{pH}$ & Immersion time (min) & Solubility index (SI) \\
\hline \multirow{2}{*}{ Simple } & & 3 & $>5^{a}$ & $1.000 \pm 0.000^{a}$ \\
& G-M & 5 & $>5^{a}$ & $1.000 \pm 0.000^{a}$ \\
& & 7 & $>5^{a}$ & $1.000 \pm 0.000^{a}$ \\
& & 3 & $>5^{a}$ & $0.356 \pm 0.025^{b}$ \\
Ch-M(G-M) & 5 & $>5^{a}$ & $0.361 \pm 0.010^{b}$ \\
& & 7 & $>5^{a}$ & $0.339 \pm 0.031^{c}$ \\
& & 3 & $>5^{a}$ & $0.488 \pm 0.047^{d}$ \\
& & & $>5^{a}$ & $0.433 \pm 0.011^{e}$ \\
& & $>5^{a}$ & $0.425 \pm 0.002^{e}$ \\
\hline
\end{tabular}

${ }^{a-e}$ Different letters in the same column indicate significant difference $(\mathrm{p}<0.05)$ by Tukey test Ch: chitosan, M: maltodextrin, I: inulin, G: gelatin

\section{Conclusions}

Double microencapsulation for probiotics by spray drying is a good alternative method for the production of insoluble powders when selecting chitosan as coating material. In this study, it was demonstrated that chitosan was effective for probiotic microencapsulation when it was exposed to gastric acid conditions when the probiotic was double encapsulated, thus maintaining its viability for further release in the colon. The use of different mixtures of coating materials (chitosan, inulin, maltodextrin and gelatin) produced stable powder microcapsules with different powder reconstitution properties, expanding the options for probiotics application in different food products.

\section{Acknowledgements}

Author Flores-Belmont acknowledges the financial support for her master degree studies to Universidad de las Américas Puebla (UDLAP) and the National Council of Science and Technology of Mexico (CONACyT).

\section{References}

Adamiec, J. \& Modrzejewska, Z. (2005). Some structural properties of spray-dried chitosan microgranules. Drying Technology, 23(8), 1601-1611. 10th Polish Drying
Symposium, Lodz, POLAND, SEP, 2003. doi:10.1081/DRT-200064989

Amin, T., Thakur, M., Jain, S., et al. (2013). Microencapsulation-the future of probiotic cultures. Journal of Microbiology, Biotechnology and Food Sciences, 3(1), 35-43.

Anal, A. K. \& Singh, H. (2007). Recent advances in microencapsulation of probiotics for industrial applications and targeted delivery. Trends in Food Science \& Technology, 18(5), 240-251. doi:10.1016/j.tifs.2007.01. 004

Ananta, E., Volkert, M., \& Knorr, D. (2005). Cellular injuries and storage stability of spray-dried lactobacillus rhamnosus gg. International Dairy Journal, 15(4), 399-409. doi:10.1016/j.idairyj.2004.08.004

AOAC. (2000). Official methods of analysis (17 th ed.) Gaithersburg: Association of Official Analytical Chemists.

Avila-Reyes, S. V., Garcia-Suarez, F. J., Teresa Jimenez, M., San Martin-Gonzalez, M. F., \& Bello-Perez, L. A. (2014). Protection of 1. rhamnosus by spray-drying using two prebiotics colloids to enhance the viability. Carbohydrate Polymers, 102, 423-430. doi:10.1016/j.carbpol.2013.11.033

Barboza, Y., Marquez, E., Parra, K., Patricia Pinero, M., \& Medina, L. M. (2012). Development of a potential functional food prepared with pigeon pea (cajanus cajan), oats and lactobacillus reuteri atcc 55730 . International Journal of Food Sciences and 
Nutrition, 63(7), 813-820. doi:10.3109/ 09637486.2012 .681633

Chávez, B. E. \& Ledeboer, A. M. (2007). Drying of probiotics: optimization of formulation and process to enhance storage survival. Drying Technology, 25(7-8), 11931201. doi:10.1080/07373930701438576

Chen, K. N., Chen, M. J., Liu, J. R., Lin, C. W., \& Chiu, H. Y. (2005). Optimization of incorporated prebiotics as coating materials for probiotic microencapsulation. Journal of Food Science, 70(5), M260-M266.

Corcoran, B. M., Ross, R. P., Fitzgerald, G. F., \& Stanton, C. (2004). Comparative survival of probiotic lactobacilli spray-dried in the presence of prebiotic substances. Journal of Applied Microbiology, 96(5), 1024-1039. doi:10.1111/j.1365-2672.2004.02219.x

Corona-Hernandez, R. I., Alvarez-Parrilla, E., Lizardi-Mendoza, J., Islas-Rubio, A. R., de la Rosa, L. A., \& Wall-Medrano, A. (2013). Structural stability and viability of microencapsulated probiotic bacteria: a review. Comprehensive Reviews in Food Science and Food Safety, 12(6), 614-628. doi:10.1111/1541-4337.12030

Desai, K. G. H. \& Park, H. J. (2005). Recent developments in microencapsulation of food ingredients. Drying Technology, 23(7), 1361-1394. doi:10 . 1081 / DRT 200063478

Desmond, C., Ross, R. P., O'Callaghan, E., Fitzgerald, G., \& Stanton, C. (2002). Improved survival of lactobacillus paracasei nfbc 338 in spray-dried powders containing gum acacia. Journal of Applied Microbiology, 93(6), 1003-1011. doi:10.1046/j.13652672.2002.01782.x

Di Criscio, T., Fratianni, A., Mignogna, R., Cinquanta, L., Coppola, R., Sorrentino, E., \& Panfili, G. (2010). Production of functional probiotic, prebiotic, and synbiotic ice creams. Journal of Dairy Science, 93(10), 4555-4564. doi:10.3168/jds.2010-3355

Ding, W. K. \& Shah, N. P. (2007). Acid, bile, and heat tolerance of free and microencapsulated probiotic bacteria. Journal of Food Science, 72(9), M446-M450. doi:10.1111/ j.1750-3841.2007.00565.x
Estevinho, B. N., Rocha, F., Santos, L., \& Alves, A. (2013). Microencapsulation with chitosan by spray drying for industr applications a review. Trends in Food Science 8 Technology, 31(2), 138-155. doi:10.1016/j. tifs.2013.04.001

Fritzen-Freire, C. B., Prudencio, E. S., Amboni, R. D. M. C., Pinto, S. S., NegraoMurakami, A. N., \& Murakami, F. S. (2012). Microencapsulation of bifidobacteria by spray drying in the presence of prebiotics. Food Research International, 45(1), 306-312. doi:10.1016/j.foodres.2011.09.020

Fuchs, M., Turchiuli, C., Bohin, M., Cuvelier, M. E., Ordonnaud, C., Peyrat-Maillard, M. N., \& Dumoulin, E. (2006). Encapsulation of oil in powder using spray drying and fluidised bed agglomeration. Journal of Food Engineering, 75(1), 27-35. doi:10. 1016/j.jfoodeng.2005.03.047

Gawkowski, D. \& Chikindas, M. L. (2013). Nondairy probiotic beverages: the next step into human health. Beneficial Microbes, 4 (2), 127-142. doi:10.3920/BM2012.0030

Gbassi, G. K. \& Vandamme, T. (2012). Probiotic encapsulation technology: from microencapsulation to release into the gut. Pharmaceutics, 4(1), 149-163.

Gharsallaoui, A., Roudaut, G., Chambin, O., Voilley, A., \& Saurel, R. (2007). Applications of spray-drying in microencapsulation of food ingredients: an overview. Food Research International, 40(9), 1107-1121. doi:10.1016/j.foodres.2007.07.004

Granato, D., Branco, G. F., Nazzaro, F., Cruz, A. G., \& Faria, J. A. F. (2010). Functional foods and nondairy probiotic food development: trends, concepts, and products. Comprehensive Reviews in Food Science and Food Safety, 9(3), 292-302.

Hernández-Carranza, P., López-Malo, A., \& Jiménez-Munguía, M.-T. (2013). Microencapsulation quality and efficiency of lactobacillus casei by spray drying using maltodextrin and vegetable extracts. Journal of Food Research, 3(1), 61-69.

Ivanovska, T. P., Petrusevska-Tozi, L., Kostoska, M. D., Geskovski, N., Grozdanov, A., Stain, C., ... Mladenovska, K. (2012). Microencapsulation of lactobacillus casei 
in chitosan-ca-alginate microparticles using spray-drying method. Macedonian Journal Of Chemistry And Chemical Engineering, $31(1), 115-123$.

Kailasapathy, K. (2006). Survival of free and encapsulated probiotic bacteria and their effect on the sensory properties of yoghurt. LWT-Food Science and Technology, 39(10), 1221-1227. doi:10.1016/j.lwt.2005. 07.013

Karimi, R., Mortazavian, A. M., \& Da Cruz, A. G. (2011). Viability of probiotic microorganisms in cheese during production and storage: a review. Dairy Science $\&$ Technology, 91(3), 283-308. doi:10.1007/ s13594-011-0005-X

Lee, J. S., Cha, D. S., \& Park, H. J. (2004). Survival of freeze-dried lactobacillus bulgaricus kfri 673 in chitosan-coated calcium alginate microparticles. Journal of Agricultural and Food Chemistry, 52(24), 73007305. doi:10.1021/jf040235k

Rokka, S. \& Rantamaki, P. (2010). Protecting probiotic bacteria by microencapsulation: challenges for industrial applications. European Food Research and Technology, 231(1), 1-12. doi:10 . 1007 / s00217 - 010 1246-2

Schubert, H. (1987). Food particle technology. part i: properties of particles and particulate food systems. Journal of Food Engineering, 6(1), 1-32. doi:10.1016/02608774(87)90019-7

Telang, A. M. \& Thorat, B. N. (2010). Optimization of process parameters for spray drying of fermented soy milk. Drying Technology, 28(12), 1445-1456. doi:10.1080/07373937. 2010.482694

Teoh, P. L., Mirhosseini, H., Mustafa, S., Hussin, A. S. M., \& Manap, M. Y. A. (2011). Recent approaches in the development of encapsulated delivery systems for probiotics. Food Biotechnology, 25(1), 77-101. doi:10. 1080/08905436.2011.547332

Urbanska, A. M., Bhathena, J., \& Prakash, S. (2007). Live encapsulated lactobacillus acidophilus cells in yogurt for therapeutic oral delivery: preparation and in vitro analysis of alginate-chitosan microcapsules. Canadian Journal of Physiology and Pharmacol- ogy, 85(9), 884-893. 1st Annual Meeting of the Natural-Health-Products-ResearchSociety-of-Canada, Montreal, CANADA, FEB, 2004. doi:10.1139/Y07-057 